\title{
Presence of a functional flagellar cluster Flag-2 and low-temperature expression of flagellar genes in Yersinia enterocolitica W22703
}

Correspondence

Thilo M. Fuchs

thilo.fuchs@wzw.tum.de

Received 27 April 2007

Revised 28 September 2007

Accepted 5 October 2007

\author{
Geraldine Bresolin, Janja Trček, Siegfried Scherer and Thilo M. Fuchs
}

Zentralinstitut für Ernährungs- und Lebensmittelforschung (ZIEL), Abteilung Mikrobiologie,
Technische Universität München, Weihenstephaner Berg 3, 85354 Freising, Germany

Twelve Yersinia enterocolitica mutants carrying luxCDABE-transposon insertions in motility and chemotaxis genes were isolated on the basis of strong low-temperature induction. Two transposons were located within an $11.2 \mathrm{~kb}$ enteric flagellar cluster 2 (Flag-2) of $Y$. enterocolitica biotype 2, serotype $\mathrm{O}: 9$ strain W22703. The Flag-2 gene cluster is absent from the corresponding genomic location of the sequenced strain $Y$. enterocolitica biotype $1 \mathrm{~B}$, serotype $\mathrm{O}: 8$ strain 8081 . Evidence for the functionality of the $\mathrm{O}: 9 \mathrm{Flag}-2$ genes, probably located within the plasticity zone of the genome, is provided by swarming assays. PCR analysis of 49 strains revealed the presence of Flag-2 genes in biotypes $2-5$, but not in biotypes $1 \mathrm{~A}$ or $1 \mathrm{~B}$.

Bioluminescence, measured between 6 and $37{ }^{\circ} \mathrm{C}$, showed that the expression of all genes located in Flag-2 and in the known flagellar cluster, Flag-1, was highest at approximately $20{ }^{\circ} \mathrm{C}$, and that expression of two Flag-2 genes is FlhC-dependent. In a motility assay, a non-motile and a hyper-motile phenotype resulted from knockout mutations of the Flag-1 genes fliS1 and fliT, respectively. Complemented strains validated these results, confirming the regulatory role of FliT.

\section{INTRODUCTION}

Yersinia enterocolitica belongs to the family Enterobacteriaceae and is a psychrotolerant, peritrichously flagellated human pathogen that causes a range of gastrointestinal diseases (Bottone, 1999). This Gram-negative, rod-shaped micro-organism is widely distributed in nature and able to survive for extended periods in terrestrial and aquatic environments at ambient temperature. The bacterium has been isolated from numerous species including flies (Fukushima et al., 1979; Rahuma et al., 2005). Swine have been identified as a major source of human infection (Bottone, 1997; Fredriksson-Ahomaa et al., 2006). A multiphasic life cycle, which comprises a free-living phase, a potential insect-associated phase and a host-dependent phase, may be characteristic of biotypes $2-4$ of this pathogen (Bresolin et al., 2006b).

In $Y$. enterocolitica, low temperature is a key environmental factor for the expression of several genes important for survival outside mammalian hosts (Bresolin et al., 2006a; Kapatral et al., 2004) as well as for the coordinate expression and assembly of the flagellar structure

Abbreviation: RLU, relative light units.

The GenBank/EMBL/DDBJ accession number for the Flag-2 sequence of Yersinia enterocolitica is AM600695.

A supplementary table listing the primers used is available with the online version of this paper.
(Kapatral \& Minnich, 1995; Kapatral et al., 2004; Rohde et al., 1994). So far, all functional flagellar genes of $Y$. enterocolitica have been found to be located in the common flagellar cluster 1 (Flag-1), which is also required for full virulence (Young et al., 2000). A second, but inactive, flagellar cluster, termed Flag-2, has been found in around one-fifth of Escherichia coli strains tested and also in Yersinia pestis and Yersinia pseudotuberculosis, but not in $Y$. enterocolitica 8081 (Ren et al., 2005). The distribution of Flag-2 in the $Y$. enterocolitica biotypes has not been investigated.

Except for some distinct differences, the flagellar hierarchy in Y. enterocolitica resembles that of E. coli and Salmonella spp. (Horne \& Pruss, 2006), in which the regulation and function of flagellar genes are well understood. Their genomes contain more than 50 flagellar genes, which can be categorized into three promoter classes. These correspond to the temporal requirements for flagellar gene products during the morphological development of the flagellum, which consists of a membrane-spanning hookbasal-body and an external structure (Aldridge \& Hughes, 2002; Chilcott \& Hughes, 2000). The regulation of flagellar gene expression is coordinated by the flhDC master operon, which is transcribed in a temperature-independent manner from a class 1 promoter (Kapatral et al., 2004). FlhD and FlhC act as transcriptional activators for class 2 promoters including the transcriptional regulators FliA $\left(\sigma^{28}\right)$ and FlgM $\left(\right.$ anti- $\left.\sigma^{28}\right)$ and genes required for the 
formation of the hook-basal-body. Most genes necessary for late flagellar morphogenesis, motor rotation and chemotactic signalling are transcribed from class 3 promoters. Rohde et al. (1994) reported $23{ }^{\circ} \mathrm{C}$ as being the temperature for maximal flagellar gene expression. However, little is known about the induction and transcription of flagellar genes in $Y$. enterocolitica at temperatures below $25{ }^{\circ} \mathrm{C}$, and in what way their expression differs from that in related species.

In this study, screening of a luxCDABE-reporter mutant library of $Y$. enterocolitica W22703 at low temperature identified transposon insertions within 12 genes involved in motility and chemotaxis. Sequence analysis of two mutants revealed a strain-specific flagellar region, which is homologous to the flagellar cluster Flag-2 of Y. pestis and $Y$. pseudotuberculosis. FlhC-dependent expression of Flag-2 genes is demonstrated, and evidence for their functionality is provided. Furthermore, we show that Flag-1 and Flag-2 genes are maximally expressed at approximately $20{ }^{\circ} \mathrm{C}$, indicating that enhanced motility is part of the psychrotolerant life style of $Y$. enterocolitica, which includes survival and growth at environmental temperatures.

\section{METHODS}

Bacterial strains, plasmids and growth conditions. Bacterial strains and plasmids used in this study are listed in Tables 1 and 3. All cultures were grown in LB broth ( $10 \mathrm{~g}$ tryptone $1^{-1}, 5 \mathrm{~g}$ yeast extract $1^{-1}$ and $5 \mathrm{~g} \mathrm{NaCl} \mathrm{l}^{-1}$ ) or on LB agar (LB broth supplemented with $1.5 \%, \mathrm{w} / \mathrm{v}$, agar). E. coli was grown at $37^{\circ} \mathrm{C}$ and Y. enterocolitica at the temperatures indicated below. If appropriate, the media were supplemented with the following antibiotics: $20 \mu \mathrm{g}$ chloramphenicol $\mathrm{ml}^{-1}, 50 \mu \mathrm{g}$ kanamycin $\mathrm{ml}^{-1}, 20 \mu \mathrm{g}$ nalidixic acid $\mathrm{ml}^{-1}$ or $18 \mu \mathrm{g}$ tetracycline $\mathrm{ml}^{-1}$ (for E. coli) and $12 \mu \mathrm{g}$ tetracycline $\mathrm{ml}^{-1}$ (for $Y$. enterocolitica).

General molecular techniques. DNA manipulation was performed according to standard procedures (Sambrook \& Russell, 2001). To isolate chromosomal DNA, $1.5 \mathrm{ml}$ of bacterial culture was centrifuged, and the sediment was resuspended in $400 \mu \mathrm{l}$ lysis buffer (100 mM Tris, pH 8.0, $5 \mathrm{mM}$ EDTA, $200 \mathrm{mM} \mathrm{NaCl}$ ). After incubation for $15 \mathrm{~min}$ on ice, $10 \mu \mathrm{l} 10 \%$ SDS and $5 \mu \mathrm{l}$ proteinase $\mathrm{K}\left(10 \mathrm{mg} \mathrm{ml}^{-1}\right)$ were added, and the sample was incubated at $55{ }^{\circ} \mathrm{C}$ overnight. The chromosomal DNA was then precipitated with $500 \mu \mathrm{l}$ 2-propanol, washed in ethanol, dried and dissolved in $500 \mu \mathrm{l} \mathrm{TE}$ buffer (10 mM Tris/HCl, $1 \mathrm{mM} \mathrm{Na} \mathrm{N}_{2}$ EDTA, $\mathrm{pH}$ 7.4) containing $1 \mu \mathrm{l}$ RNase $\left(10 \mathrm{mg} \mathrm{ml}^{-1}\right)$. Transposon mutagenesis using pUT mini-Tn5 luxCDABE Km2 and mating with E. coli S17.1 $\lambda$ pir as the donor strain has been described elsewhere (Bresolin et al., 2006a). PCRs were carried out with Taq polymerase (Fermentas) using the following programme: one cycle at $95{ }^{\circ} \mathrm{C}$ for $2 \mathrm{~min} ; 30$ cycles at $95{ }^{\circ} \mathrm{C}$ for $10 \mathrm{~s}$, at the appropriate annealing temperature for $30 \mathrm{~s}$, and at $72{ }^{\circ} \mathrm{C}$ for 45-180 s depending on the expected fragment length; one cycle at $72{ }^{\circ} \mathrm{C}$ for $10 \mathrm{~min}$. All primers are listed in Supplementary Table S1, available with the online version of this paper. Chromosomal DNA $\left(100 \mathrm{ng}^{-1} \mathrm{l}^{-1}\right.$ ) was used as a template for PCR amplification.

Inverse PCR and DNA sequencing. Identification and characterization of transposon insertion sites was performed by inverse PCR (Bresolin et al., 2006a). Briefly, $400 \mathrm{ng}$ chromosomal DNA of each transposon mutant was completely digested with ClaI, HindIII or SspI (Fermentas), enzymes were heat-inactivated and fragments were treated with T4 DNA ligase (Invitrogen) to allow self-ligation, resulting in circular molecules. Subsequent inverse PCR (Ochman et al., 1990) was performed using transposon-specific primers derived from the O-end or the I-end of mini-Tn5 (Table S1). The PCR fragments obtained were sequenced by MWG-Biotech with primers hybridizing to a $100 \mathrm{bp}$ transposon region near the O-end or the I-end.

Sequencing of strain-specific DNA was performed by inverse PCR (as described above) using the restriction enzymes HaeIII (USB), HhaI, HindIII, HpaI, MspI, MunI, RsaI, SspI and VspI (Fermentas) and primers listed in Table S1. Sequencing was performed by 4 base lab.

Bioinformatics. Mapping of mini-Tn5 luxCDABE insertions was performed with the $Y$. enterocolitica BLAST Server from the Sanger Institute (http://www.sanger.ac.uk/cgi-bin/blast/submitblast/y_enterocolitica). Sequences without similarities to the sequence of $Y$. enterocolitica 8081 (accession no. AM286415/AM286416) were classified as specific for strain W22703, used in this study. Sequence assembly was done with Vector NTI Advance (Invitrogen). The resulting sequence was annotated using the NCBI ORF-Finder (http:// www.ncbi.nlm.nih.gov/gorf/gorf.html). Homology searches of the single ORFs were performed with BLASTP from NCBI (http:// www.ncbi.nlm.nih.gov/BLAST/). Promoter sequences located upstream of the identified genes were deduced using a promoter prediction program (http://www.fruitfly.org/seq_tools/promoter.html). The accession number of the $Y$. pseudotuberculosis genome sequence is NC_006155.

Measuring expression profiles using a luxCDABE reporter. Bioluminescence measurements were performed in white 96-well plates with clear bottoms (Matrix Technologies). Transposon mutants were grown overnight at $30{ }^{\circ} \mathrm{C}$ with shaking (500 r.p.m.) in deep-well microtitre plates filled with $800 \mu \mathrm{l}$ selective LB broth, and then $1: 4000$ diluted in $200 \mu \mathrm{l} \mathrm{LB}$ broth with kanamycin. For investigation of the expression profiles, the plates were incubated at $6,10,15,20$, 25, 30 and $37^{\circ} \mathrm{C}$. Bioluminescence (at $490 \mathrm{~nm}$ ) and $\mathrm{OD}_{405}$ of all plates were measured in parallel using a Wallac VICTOR ${ }^{2} 1420$ multilabel counter (Perkin Elmer Life Sciences). Bioluminescence was recorded as relative light units (RLU), and background activity of 0.15 RLU was subtracted. Cells were measured in the late exponential phase $\left(\mathrm{OD}_{405} \sim 0.8-0.9\right)$. To allow a direct comparison of results obtained at all temperatures applied, RLU were related to the growth of cells (RLU/OD).

Complementation of W22703-fliS1::Tn5/ux and W22703fliT: : Tn5/ux. The complete coding sequence of fliS1 (YE2525) and 411 nucleotides of its upstream sequence, as well as the coding sequence of $f l i T$ (YE2526) and 207 nucleotides located upstream, were amplified at an annealing temperature of $50{ }^{\circ} \mathrm{C}$ and with an elongation time of 2 min using the oligonucleotides HAPF1/fliTR1 and fliSF1/ybcMR1 (Table S1), respectively. Each fragment was digested with EcoRI and cloned separately into the EcoRI site of pACYC184, resulting in the recombinant plasmids pACYC184/fliS1 and pACYC184/fliT. Cloning was performed in E. coli DH5 $\alpha$ MCR and constructs were confirmed by PCR and restriction analysis. The direction of gene transcription corresponds to that of the disrupted plasmid gene encoding chloramphenicol acetyltransferase. Plasmid constructs were transformed by electroporation into the respective $Y$. enterocolitica mutant strains.

Construction of insertional knockout mutants. Knockout mutants of the putative flagellin gene flaA (orf9), the putative regulatory gene (orf10) and the hook-length-control gene fliK (orf5) of the new flagellar region Flag-2 as well as the flagellar regulatory gene $f h D C$ were generated by plasmid insertion via homologous recombination. Short intragenic fragments of the target genes were 
Table 1. Strains and plasmids used in this study

Numbers in parentheses indicate the Tn5 insertion site with respect to the gene.

\begin{tabular}{|c|c|c|}
\hline Strain/Plasmid & Relevant characteristics & Reference or source \\
\hline \multicolumn{3}{|l|}{ Strains } \\
\hline E. coli S17.1 $\lambda$ pir & 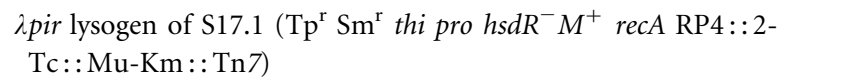 & Simon et al. (1983) \\
\hline E. coli $\mathrm{DH} 5 \alpha \mathrm{MCR}$ & $\begin{array}{l}F^{-} \text {mcrA } \Delta(\text { mcr-hsdRMS-mcrBC) } \phi 80 \text { lacZ } \Delta M 15 \\
\quad \Delta(\text { lacZYA-argF }) \text { U169 recA-1 endA-1 supE-44 thi-1 gyrA-96 relA-1 }\end{array}$ & Invitrogen \\
\hline Y. enterocolitica W22703 & Biotype 2, serotype O:9, $\mathrm{Nal}^{\mathrm{r}}, \mathrm{Res}^{-}, \mathrm{Mod}^{+}, \mathrm{pYV}^{-}$ & Cornelis \& Colson (1975) \\
\hline Y. enterocolitica 8081 & Biotype $1 \mathrm{~B}$, serotype $\mathrm{O}: 8, \mathrm{Nal}^{\mathrm{r}}$ & V. Miller, St Louis, USA \\
\hline W22703-fliB(434):: Tn5lux & $\begin{array}{l}\text { W22703 with luxCDABE reporter inserted into YE2520 (Flag-1) } \\
\text { encoding flagellin N-methylase }\end{array}$ & Bresolin et al. (2006a) \\
\hline W22703-fleC(963):: Tn5lux & As above, into YE2521 (Flag-1) encoding flagellin & Bresolin et al. (2006a) \\
\hline W22703-fliS1(9):: Tn5lux & $\begin{array}{l}\text { As above, intoYE2525 (Flag-1) encoding a putative flagellin-specific } \\
\text { chaperon }\end{array}$ & Bresolin et al. (2006a) \\
\hline W22703-fliT(119):: Tn5lux & $\begin{array}{l}\text { As above, into YE2526 (Flag-1) encoding a putative regulatory } \\
\text { protein }\end{array}$ & Bresolin et al. (2006a) \\
\hline W22703-ybcM(30):: Tn5lux & $\begin{array}{l}\text { As above, into YE2527 (Flag-1) encoding a putative AraC type } \\
\text { regulatory protein }\end{array}$ & Bresolin et al. (2006a) \\
\hline W22703-fliF(1027):: Tn5lux & $\begin{array}{l}\text { As above, into YE2537 (Flag-1) encoding a flagellar basal body } \\
\text { M-ring protein }\end{array}$ & Bresolin et al. (2006a) \\
\hline W22703-2575(797):: Tn5lux & $\begin{array}{l}\text { As above, into YE2575 encoding a methyl-accepting chemotaxis } \\
\text { protein }\end{array}$ & Bresolin et al. (2006a) \\
\hline W22703-cheA(1437):: Tn5lux & As above, into YE2577 encoding chemotaxis protein CheA & Bresolin et al. (2006a) \\
\hline W22703-YE2673:: Tn5lux & $\begin{array}{l}\text { W22703 with luxCDABE reporter inserted } 68 \mathrm{bp} \text { downstream of } \\
\text { YE2673 encoding a putative chemotaxis signal transduction protein }\end{array}$ & Bresolin et al. (2006a) \\
\hline W22703-YE2848(285)::Tn5lux & $\begin{array}{l}\text { W22703 with } \operatorname{luxCDABE} \text { reporter inserted into YE2848 encoding a } \\
\text { putative chemotaxis methyl-accepting transducer }\end{array}$ & Bresolin et al. (2006a) \\
\hline W22703-fliD2: : Tn5lux & $\begin{array}{l}\text { As above, into } f l i D \text { (Flag- } 2 \text { ) encoding a flagellar hook-associated } \\
\text { protein; four independent insertions at nucleotide positions } 311 \text {, } \\
458,507 \text {, and } 1156\end{array}$ & This study \\
\hline W22703-fliS2(238):: Tn5lux & As above, into fliS (Flag-2) & This study \\
\hline W22703-flaA(214)::pKRG9 & W22703 with disrupted putative flagellin gene (Flag-2) & This study \\
\hline W22703-orf10(171)::pKRG9 & W22703 with disrupted putative regulatory gene (Flag-2) & This study \\
\hline W22703-fliK(181)::pKRG9 & W22703 with disrupted hook-length control gene (Flag-2) & This study \\
\hline W22703-fliD2:: Tn5lux-flhC::pKRG9 & W22703 with double knockout of fliD2 and $f l h C$ & This study \\
\hline W22703-fliS2:: Tn5lux-flhC::pKRG9 & W22703 with double knockout of fliS2 and flhC & This study \\
\hline W22703-fleC::Tn5lux-flhC::pKRG9 & W22703 with double knockout of $f l e C$ and $f l h C$ & This study \\
\hline W22703-fliT: : Tn5lux-flhC:: pKRG9 & W22703 with double knockout of $f l i T$ and $f l h C$ & This study \\
\hline W22703-YE2848:: Tn5lux-flaA::pKRG9 & W22703 with double knockout of YE2848 and flhC & This study \\
\hline W22703-YE2673:: Tn5lux-flaA::pKRG9 & W22703 with double knockout of YE2673 and flhC & This study \\
\hline W22703-fleC::Tn5lux-flaA::pKRG9 & W22703 with double knockout of fleC and flaA & This study \\
\hline \multicolumn{3}{|l|}{ Plasmids } \\
\hline pUT mini-Tn5 luxCDABE Km2 & $\begin{array}{l}\text { Suicide vector, ori } \mathrm{R} 6 \mathrm{~K}, \text { mini-Tn5 Km2 luxCDABE transposon, } \\
m o b^{+}(\mathrm{RP} 4), \mathrm{Ap}^{\mathrm{r}} \mathrm{Km}^{\mathrm{r}}\end{array}$ & Winson et al. (1998) \\
\hline pACYC184 & Cloning vector, $\mathrm{P} 15 \mathrm{~A}$ origin, $\mathrm{Cm}^{\mathrm{r}} \mathrm{Tc}^{\mathrm{r}}$ & Chang \& Cohen (1978) \\
\hline pACYC184/fliS1 & $\begin{array}{l}\text { pACYC184 with an } 876 \text { bp EcoRI fragment carrying fliS1 (YE2525) } \\
\text { and } 411 \text { bp of its upstream region }\end{array}$ & This study \\
\hline pACYC184/fliT & $\begin{array}{l}\text { pACYC184 with an } 891 \mathrm{bp} \text { EcoRI fragment carrying fliT (YE2526) } \\
\text { and } 207 \text { bp of its upstream region }\end{array}$ & This study \\
\hline pKRG9 & $\begin{array}{l}\text { Derivative of suicide vector pGP704; ori R6K, } \mathrm{mob}^{+} \text {(RP4), } \\
\mathrm{Cm}^{\mathrm{r}} \mathrm{Ap}^{\mathrm{s}}\end{array}$ & Creatogen \\
\hline pKRG-flaA' & pKRG9 with a 774 bp intragenic fragment of flaA (Flag-2) & This study \\
\hline pKRG-orf $10^{\prime}$ & $\begin{array}{l}\text { pKRG9 with a } 747 \text { bp intragenic fragment of a putative regulatory } \\
\text { gene (Flag- } 2 \text { ) }\end{array}$ & This study \\
\hline pKRG-fliK' & pKRG9 with a 389 bp intragenic fragment of $f l i K$ (Flag-2) & This study \\
\hline pKRG-flhDC' & pKRG9 with a 463 bp intragenic fragment of $f l h D C$ & This study \\
\hline
\end{tabular}


amplified from $Y$. enterocolitica chromosomal DNA using primers listed in Table S1. Fragments were digested with $X b a \mathrm{I}$ and SacI

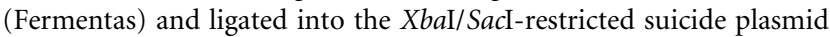
pKRG9. The recombinant plasmids were transformed into E. coli S17.1 $\lambda$ pir by electroporation and transferred into Y. enterocolitica W22703 via plate mating. For this purpose, five colonies of donor strain and approximately 20 colonies of recipient strain were mixed on an LB agar plate and incubated for $6 \mathrm{~h}$ at $30^{\circ} \mathrm{C}$. The complete lawn was scraped off the plate and resuspended in $1 \mathrm{ml} \mathrm{LB}$ medium. Serial dilutions were prepared and conjugants were selected on plates containing nalidixic acid and chloramphenicol. To exclude illegitimate recombination, the correct insertion of the recombinant plasmid was confirmed by PCR using a gene-specific primer or a cloning primer, and a plasmid-derived primer (Table S1).

Motility assay. Motility was tested by assessing swimming phenotypes on motility agar (LB medium containing $0.3 \%$ agar without antibiotics). Streak cultures of $Y$. enterocolitica wild-type, mutant and complementing strains were prepared on LB agar plates containing the appropriate antibiotics and incubated overnight at $30{ }^{\circ} \mathrm{C}$. From these plates single colonies were stabbed onto motility agar plates and incubated initially for $2 \mathrm{~h}$ at $37^{\circ} \mathrm{C}$ to start the assay with non-motile bacteria. The plates were subsequently incubated at $15{ }^{\circ} \mathrm{C}(44 \mathrm{~h}), 20{ }^{\circ} \mathrm{C}(21 \mathrm{~h}), 25{ }^{\circ} \mathrm{C}(21 \mathrm{~h})$ and $30{ }^{\circ} \mathrm{C}(42 \mathrm{~h})$.

\section{RESULTS}

\section{Y. enterocolitica W22703 carries a flagellar region homologous to Flag-2}

We recently reported the identification of luxCDABE insertions into the genome of $Y$. enterocolitica strain W22703 that resulted in increased light emission at $10{ }^{\circ} \mathrm{C}$ as compared to $30{ }^{\circ} \mathrm{C}$ (Bresolin et al., 2006a). Among mutants with strongly elevated light emission, we identified 21 clones harbouring transposon insertions in 12 different genes associated with motility and chemotaxis (Table 1; Fig. 1a), six of which are part of the Flag-1 cluster. Interestingly, five insertion sites were located within a different genome region of W22703 showing significant homologies to flagellar genes of $Y$. pestis (Fig. 1b) and $Y$. pseudotuberculosis. The sequences of these five transposon mutants were assembled into a $2367 \mathrm{bp}$ fragment that was extended by inverse PCR to a total of $11526 \mathrm{bp}$. BLASTN analysis revealed that $290 \mathrm{bp}$ at the very $5^{\prime}$-end of this fragment were identical to the sequence of YE3610 within the $Y$. enterocolitica 8081 genome sequence. No further sequence identities were observed, indicating that the $11.2 \mathrm{~kb}$ region is absent in strain 8081 . YE3610 is located within the $199 \mathrm{~kb}$ plasticity zone of $Y$. enterocolitica 8081, which is the largest region of species-specific genomic variation found within this species (Thomson et al., 2006). Further sequence analysis resulted in the annotation of 12 ORFs (Fig. 1b) with identities of deduced amino acid sequences to proteins from other pathogenic Yersinia species and from E. coli of between $31 \%$ and $94 \%$ (Table 2). All the ORFs were highly similar to the Flag-2 genes of $Y$. pestis CO92 (Parkhill et al., 2001) and Y. pseudotuberculosis IP32953 (YPTB3329-YPTB3322) as well as to the Flag-2 flagellar cluster from E. coli 042 (Ren et al., 2005).

\section{Distribution of Flag-2 in different biotypes of $Y$. enterocolitica}

Y. enterocolitica strains W22703 and 8081 belong to biotypes 2 and $1 \mathrm{~B}$, respectively. To gain further information on the distribution of the Flag-2 gene cluster in the six biotypes of $Y$. enterocolitica, we subjected a total of 49 strains to PCR analysis using six oligonucleotides that amplify fragments I-VI of the Flag-2 gene cluster as depicted in Fig. 1(b). The strains included W22703 and 8081 as a positive- and negative control, respectively, and 47 strains that had been isolated on five continents from humans and animals (Table 3). Distinct PCR fragments were obtained when chromosomal DNA of biotypes 2-5 served as a template. In each of these reactions, the PCR product showed the expected length of $1554 \mathrm{bp}$ (I), 1834 bp (II), 1529 bp (III), 1817 bp (IV), 2171 bp (V), and $1517 \mathrm{bp}$ (VI). In contrast, none of the six primer pairs produced amplified fragments when genomic DNA of biotype $1 \mathrm{~A}$ or $1 \mathrm{~B}$ was used, with the exception of fragment III, representing flaA, which was amplified from genomic DNA of strains 213-36/89 and 214-36/84 (Table 3). The presence of Flag-1 in each strain was confirmed by the amplification of $f l i T$ using primers fliSF1 and ybcMR1. No PCR amplification was observed for two strains, 237 and SZ4501/97, and the latter strain was found to be less motile than the wild-type strain in the swarming assay (results not shown).

\section{Expression of motility and chemotaxis genes is maximal at approximately $20^{\circ} \mathrm{C}$}

Most experiments addressing temperature-dependent transcription of virulence or flagellar genes of $Y$. enterocolitica are performed within a relatively narrow temperature range $\left(24-37^{\circ} \mathrm{C}\right)$. We therefore decided to investigate the transcriptional response of all mutants with insertions into chemotaxis and flagellar genes located in Flag-1 and Flag-2 at $6,10,15,20,25,30$ and $37{ }^{\circ} \mathrm{C}$ at an $\mathrm{OD}_{405}$ between 0.8 and 0.9. Very low light emission was observed for all mutants at $37{ }^{\circ} \mathrm{C}$, with bioluminescence signals only slightly above background level (Fig. 2a, b). This finding is in accordance with the non-motile phenotype of $Y$. enterocolitica cells at human body temperature. The reporter activity of all mutants measured increased with decreasing temperature with a maximum at $20{ }^{\circ} \mathrm{C}$, with the exception of W22703-YE2575::Tn5lux (Fig. 2b) and W22703-fleC::Tn5lux (Fig. 2a), which had maximum activity at $25{ }^{\circ} \mathrm{C}$. The highest expression was observed for $\mathrm{fleC}$, which encodes a flagellin (Fig. 2a). Mutants W22703fliD2:: Tn5lux and W22703-fliS2:: Tn5lux showed another temperature optimum at $30{ }^{\circ} \mathrm{C}$ (Fig. $2 \mathrm{c}$ ), suggesting a putative role of the Flag-2 genes in virulence towards mammals. The temperature-dependent activity of enzymes involved in bioluminescence was also taken into account by using a correction factor derived from our own experimental data and the Arrhenius prediction (Bresolin et al., 2006a). This approach gave an optimal temperature of 


\section{(a) Y. enterocolitica Flag-1}

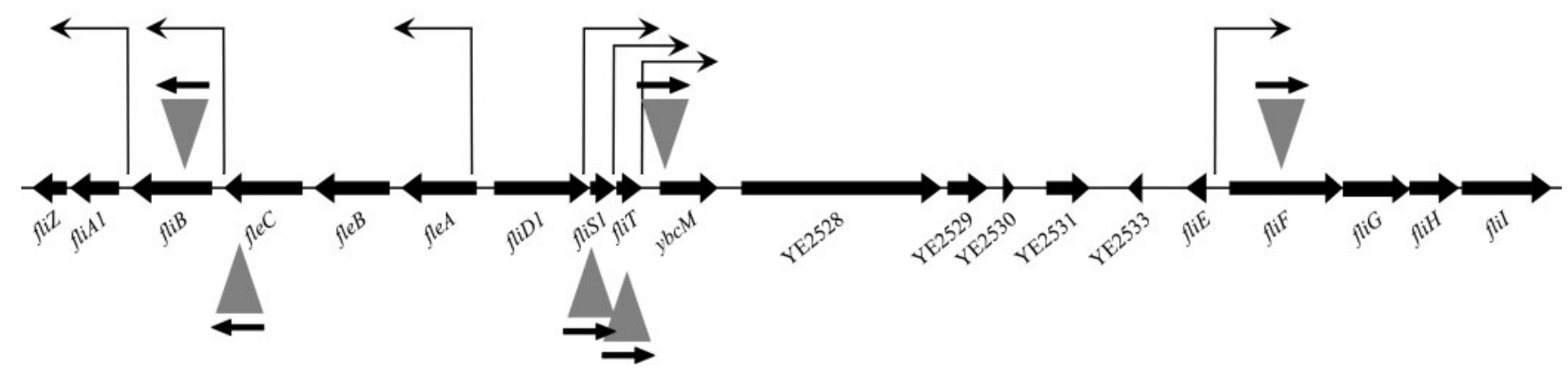

!

\section{(b) Y. enterocolitica Flag-2}

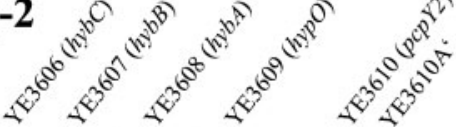

Y. enterocolitica 8081

Y. enterocolitica W22703

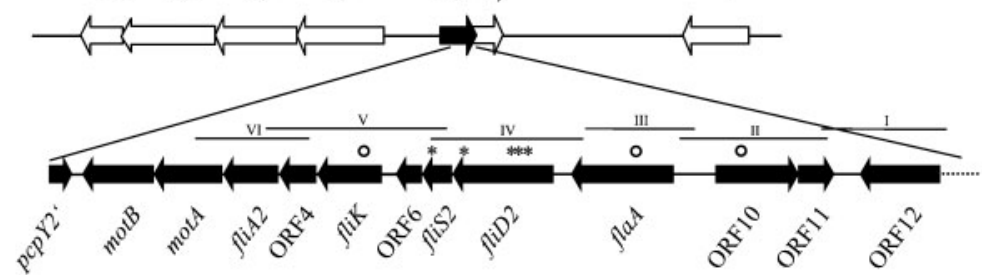

Y. pestis CO92

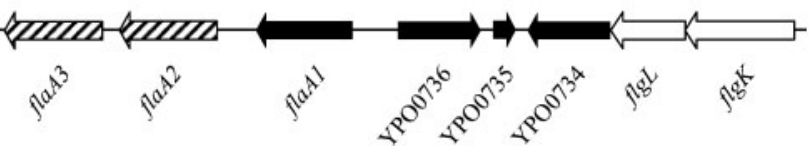

Fig. 1. (a) Partial map of the $Y$. enterocolitica 8081 flagellar cluster Flag-1. Gene organization and annotation was adapted from that used by the Sanger Institute, and gene nomenclature from Horne \& Pruss (2006). Positions and orientations of ORFs are indicated by thick black arrows, those of predicted promoters by thin bent arrows. Chromosomal mini-Tn5 luxCDABE insertions into the genome of W22703, localized by sequence analysis, are indicated by triangles. Arrows at the base of each triangle indicate the orientation of the luxCDABE operon. (b) Part of the flagellar cluster Flag-2 identified in strain W22703. The region was annotated using the NCBI ORF-Finder and compared to the genomes of $Y$. enterocolitica 8081 and $Y$. pestis CO92 (accession no. AL590842). Homologous genes are indicated by black arrows; additional genes within Flag-2 of $Y$. pestis without a homologue within the known Flag-2 sequence of strain W22703 are indicated by hatched arrows. Circles indicate three site-directed insertional mutants; asterisks indicate five transposon insertions described in Table 1. Fragments I-VI refer to the PCR analysis of Flag-2 distribution (Table 3).

15-20 ${ }^{\circ} \mathrm{C}$ for the expression of all genes investigated (data not shown).

\section{Evidence for functional Flag-2 genes}

Two genes of Flag-2, fliD2 and fliS2, also showed maximal expression at $20{ }^{\circ} \mathrm{C}$ (Fig. 2c). To investigate their regulatory dependence on the flagellar activator FlhC, flhC was mutated by insertional knockout in strains W22703-fliD2:: Tn5lux, W22703-fliS2:: Tn5lux, W22703fliT::Tn5lux and W22703-fleC::Tn5lux. The latter two served as control strains. The luciferase activity was then measured at $6-37{ }^{\circ} \mathrm{C}$. The results obtained demonstrate that not only fliT or fleC, but also the Flag-2 genes fliS2 and fliD2 are under the control of the flagellar master operon at lower temperatures (Fig. 2c).
Four transposons had inserted into an ORF encoding a putative flagellar hook-associated protein HAP (fliD2), and the fifth transposon insertion was located in the neighbouring downstream gene, termed fliS2, which encodes a flagellin-specific chaperone FliS2 (Fig. 1b). To test the functionality of Flag-2 genes in strain W22703, we generated three insertional mutants with knockouts of the putative flagellar subunit gene flaA (orf9), a predicted regulatory gene (orf10) and fliK (orf5) which is similar to flagellar hook-length-control genes. Their in vitro growth at both 15 and $30{ }^{\circ} \mathrm{C}$ was identical to that of the wild-type strain. The swimming phenotypes of the mutants were investigated in motility assays at different temperatures. We observed an increase of motility at temperatures below $30{ }^{\circ} \mathrm{C}$ (Fig. 3a). No effect on motility was observed when flaA was mutagenized in strains with a Tn5lux insertion 
Table 2. Nomenclature of ORFs of the new flagellar region in $Y$. enterocolitica W22703 as derived from identity and similarity of predicted proteins with and to sequences in the SWISS-PROT and GenBank databases

\begin{tabular}{|c|c|c|c|}
\hline Gene & $\mathbf{a a}^{\star} \mathbf{M M} \dagger$ & Homologous protein/putative function & Identity/similarity $(\%) \ddagger$ \\
\hline orf1 & 30233.5 & Flagellar motor protein MotB & $88 / 94^{Y p} ; 88 / 93^{Y p t b}$ \\
\hline orf2 & 28831.7 & Flagellar motor protein MotA & $88 / 94^{Y p t b} ; 87 / 94^{Y p}$ \\
\hline orf3 & 23126.6 & Sigma factor FliA2 & $86 / 94^{Y p t b} ; 85 / 94^{Y p}$ \\
\hline orf4 & 15517.7 & Putative flagellar biogenesis protein & $73 / 81^{Y p t b} ; 71 / 81^{Y p}$ \\
\hline orf5 & 31633.8 & Flagellar hook-length control protein FliK & $50 / 63^{Y p} ; 50 / 62^{Y p t b}$ \\
\hline orf6 & 10912.5 & Hypothetical protein & $38 / 62^{Y p} ; 38 / 60^{Y p t b}$ \\
\hline orf7 & 12714.1 & Flagellin-specific chaperone FliS2 & $58 / 75^{Y p t b} ; 58 / 75^{Y p}$ \\
\hline orf8 & 42245.7 & Putative flagellar-hook-associated protein FliD2 & $33 / 60^{Y p t b} ; 32 / 60^{Y p}$ \\
\hline orf9 & 43044.1 & Putative flagellin FlaA & $32 / 47^{Y p t b} ; 31 / 47^{Y p}$ \\
\hline orf10 & 35139.8 & Putative regulatory protein, DNA-binding winged-HTH domains & $51 / 64^{Y p t b} ; 50 / 64^{Y p}$ \\
\hline orf11 & 15317.2 & Hypothetical protein & $57 / 71^{Y p} ; 56 / 71^{Y p t b}$ \\
\hline orf12 & 33637.31 & Hypothetical protein & $45 / 63^{Y p t b} ; 44 / 63^{Y p}$ \\
\hline
\end{tabular}

*aa, length (amino acids) of product.

$\dagger \mathrm{MM}$, predicted molecular mass $(\mathrm{kDa})$ of product.

$\ddagger Y p$, Y. pestis; Yptb, Y. pseudotuberculosis.

into cheA, fleC, fliB, fliD2, fliS2, ybcM, YE2575 or YE2848 (data not shown).

\section{The fliT mutant reveals a hyper-motile phenotype in $Y$. enterocolitica}

All strains but one (W22703-YE2673::Tn5lux) were knockout mutants of $Y$. enterocolitica flagellar or chemotaxis genes. This allowed us to directly investigate the biological function of mutated Flag-1 genes in a motility assay. The in vitro growth properties of all mutants measured at 15 and $30{ }^{\circ} \mathrm{C}$ did not differ from that of strains W22703 and 8081. As expected, the knockout mutant of FliF, forming the flagellar MS ring, W22703fliF:: Tn5lux, and the two chemotaxis mutants W22703cheA::Tn5lux and W22703-2575::Tn5lux exhibited a non-motile phenotype at all temperatures tested (data not shown). W22703-fliT:: Tn5lux showed a hyper-motile phenotype at all temperatures examined, and W22703flis1::Tn5lux a non-motile phenotype below $30{ }^{\circ} \mathrm{C}$ (Fig. 3b, c). FliS1 probably acts as a cytosolic chaperone, and FliT is involved in the transcriptional regulation of flagellar genes (Auvray et al., 2001; Kutsukake et al., 1999). The motility phenotypes of the remaining transposon mutants, as well as of a fleC/flaA double mutant, did not differ from the wild-type phenotype under the tested conditions (data not shown).

To confirm the results obtained for the fliT and fliS1 mutants, the wild-type strain and the mutants W22703fliS1:: Tn5lux and W22703-fliT::Tn5lux were transformed with the constructs pACYC184/fliS1 and pACYC184/fliT, respectively. Each fragment cloned carried the putative native promoter sequence (Table 1 ). In swarming assays, the hyper-motility of W22703-fliT:: Tn5lux was drastically reduced in the presence of pACYC184/fliT (Fig. 3b). A similar non-motile phenotype resulted from fliT overexpression in the wild-type, indicating that FliT acts as repressor of flagellar synthesis in $Y$. enterocolitica. Motility of the non-motile mutant W22703-fliS1::Tn5lux was successfully restored with the plasmid pACYC184/fliS1 (Fig. 3c).

\section{DISCUSSION}

Here, we report, to our knowledge for the first time, the presence of the flagellar cluster Flag-2 in a Y. enterocolitica genome. We observed a conserved synteny with respect to the genomes of $Y$. pestis CO92 and Y. pseudotuberculosis IP32953. In strain W22730, Flag-2 is probably part of the plasticity zone, a key locus for high pathogenicity. Interestingly, remnants of Flag-2 are still present in strain 8081, indicating that a $100 \mathrm{~kb}$ deletion contributes to the high genomic variability of $Y$. enterocolitica strains (Thomson et al., 2006). By PCR analysis of 49 strains representing six biotypes, we show that the newly described flagellar region Flag-2 in $Y$. enterocolitica is specific to strains from the low-pathogenic biotypes $2-5$ and is absent from the high-pathogenic biotype $1 \mathrm{~B}$ strains and from the biotype 1A strains tested. No pseudogenes were identified among the 12 ORFs annotated. The temperature-and flhDC-dependent expression of fliD2 and fliS2 were demonstrated in this study, as well as the functionality of at least three other Flag-2 genes, fliK, flaA and orf10. Their products are predicted to be involved in flagellar hooklength control and in regulation, activities that might explain the slightly hyper-motile phenotype of the respective mutants. Due to the absence of flaA in two $Y$. enterocolitica strains, as well as the wild-type-like motility 
Table 3. $Y$. enterocolitica strains investigated for Flag-2 genes

ND, Not defined.

\begin{tabular}{|c|c|c|c|c|}
\hline Biotype & Serotype & Strain & Geographical origin & Biological origin \\
\hline $1 \mathrm{~A}$ & ND & MZ0124* & $\mathrm{ND}$ & Concentrate of whey \\
\hline $1 \mathrm{~A}$ & $\mathrm{O}: 41,43$ & SZ634/04† & Germany & Human \\
\hline $1 \mathrm{~A}$ & $\mathrm{O}: 5$ & Y755末 & France & Pony \\
\hline $1 \mathrm{~A}$ & $O: 5$ & $\mathrm{H} 79 / 83 \dagger$ & Germany & Human \\
\hline $1 \mathrm{~A}$ & $O: 5$ & $\mathrm{H} 1527 / 93 \dagger$ & Germany & Human \\
\hline $1 \mathrm{~A}$ & $\mathrm{O}: 41,43$ & $\mathrm{SZ593/04 \dagger}$ & Germany & Baby food \\
\hline $1 \mathrm{~A}$ & $\mathrm{O}: 41,43$ & SZ554/04† & Germany & Food \\
\hline $1 \mathrm{~A}$ & $\mathrm{O}: 4,33$ & SZ1167/04† & Germany & Human \\
\hline $1 \mathrm{~A}$ & $\mathrm{O}: 10$ & SZ671/04† & Germany & Human \\
\hline $1 \mathrm{~A}$ & $\mathrm{O}: 5$ & $1527-36 / 93 \dagger$ & Germany & Human \\
\hline $1 \mathrm{~A}$ & $\mathrm{O}: 5$ & SZ662/97† & Germany & Human \\
\hline $1 \mathrm{~A}$ & $\mathrm{O}: 14$ & SZ4331/97† & Germany & Human \\
\hline $1 \mathrm{~A}$ & $0: 15$ & SZ4501/97† & Germany & Human \\
\hline $1 \mathrm{~A}$ & $\mathrm{O}: 41,43$ & $767-36 / 91 \dagger$ & Germany & Human \\
\hline $1 \mathrm{~A}$ & $\mathrm{O}: 48$ & SZ4643/93† & Germany & Human \\
\hline $1 \mathrm{~A}$ & $\mathrm{O}: 19,8$ & $88 / 50 \|$ & Germany & Water \\
\hline $1 \mathrm{~A}$ & $\mathrm{O}: 5$ & $5 / 29807 I I$ & Germany & Swine \\
\hline $1 \mathrm{~A}$ & $\mathrm{O}: 50$ & $54 / 111$ & Germany & Water \\
\hline $1 \mathrm{~A}$ & $O: 6,30$ & $55 / 211$ & Germany & Liquid manure \\
\hline $1 \mathrm{~A}$ & $\mathrm{O}: 7,8$ & $53 / 30444 \|$ & Germany & Swine \\
\hline 1B & $\mathrm{O}: 8$ & SZ375/04† & Germany & Human \\
\hline 1B & $\mathrm{O}: 8$ & WA-314‡ & USA & Human \\
\hline 1B & $O: 13$ & Y293\$ & $\mathrm{ND}$ & $\mathrm{ND}$ \\
\hline 1B & $\mathrm{O}: 8$ & SZ506/04† & Germany & Human \\
\hline 1B & $\mathrm{O}: 8$ & Y286\$ & USA & $\mathrm{ND}$ \\
\hline 1B & $\mathrm{O}: 8$ & SZ5108/01† & Germany & Human \\
\hline 1B & $\mathrm{O}: 8$ & $900-36 / 90 \dagger$ & Germany & Human \\
\hline 1B & $\mathrm{O}: 8$ & $19-36 / 92 \dagger$ & Germany & Human \\
\hline 1B & $O: 21$ & $209-36 / 84 \dagger$ & Germany & Human \\
\hline 1B & $O: 21$ & $213-36 / 89 \dagger$ & Germany & Human \\
\hline 1B & $O: 21$ & $214-36 / 84 \dagger$ & Germany & Human \\
\hline 2 & $0: 9$ & H692/94† & Germany & ND \\
\hline 2 & O:9 & H621/87† & Germany & Human \\
\hline 2 & $\mathrm{O}: 5,27$ & SZ1249/04† & Germany & Human \\
\hline 2 & $O: 9$ & Y738 & France & Human \\
\hline 2 & $0: 9$ & Y127\$ & $\mathrm{ND}$ & $\mathrm{ND}$ \\
\hline $2 / 3$ & $\mathrm{O}: 5,27$ & $237 \ddagger$ & USA & $\mathrm{ND}$ \\
\hline 3 & $O: 5,27$ & $\mathrm{H} 230 / 89 \dagger$ & Germany & Human \\
\hline 3 & $\mathrm{O}: 1$ & NCTC 104609 & Denmark & Chinchilla \\
\hline 3 & $\mathrm{O}: 3$ & Y746末 & Japan & Human \\
\hline 4 & $O: 3$ & Y747末 & Sweden & Human \\
\hline 4 & $O: 3$ & Y755末 & South Africa & Human \\
\hline 4 & $\mathrm{O}: 3$ & Y769末 & New Zealand & Human \\
\hline 4 & $\mathrm{O}: 3$ & SZ425/04† & Germany & Pig tongue \\
\hline 4 & $O: 3$ & SZ687/04† & Germany & Dog faeces \\
\hline 5 & $O: 2 a, 2 b, 3$ & Y772末 & France & Hare \\
\hline 5 & $\mathrm{O}: 2 \mathrm{a}, 2 \mathrm{~b}, 3$ & Y773末 & France & Hare \\
\hline
\end{tabular}

*Authors' collection.

$\dagger$ Institut für Hygiene und Umwelt, Hamburg, Germany.

¥Max von Pettenkofer-Institut, München, Germany.

§Institut für Mikrobiologie der Bundeswehr, München, Germany.

IIRobert-Koch-Institut, Berlin, Germany.

SNational Collection of Type Cultures, London, UK. 


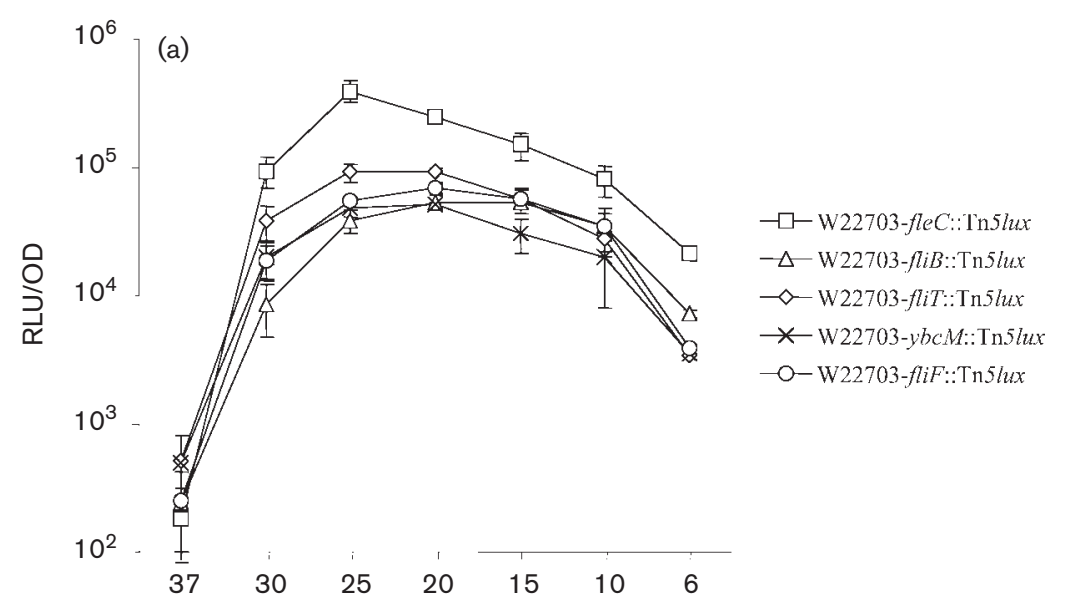

$10^{6}-(b)$
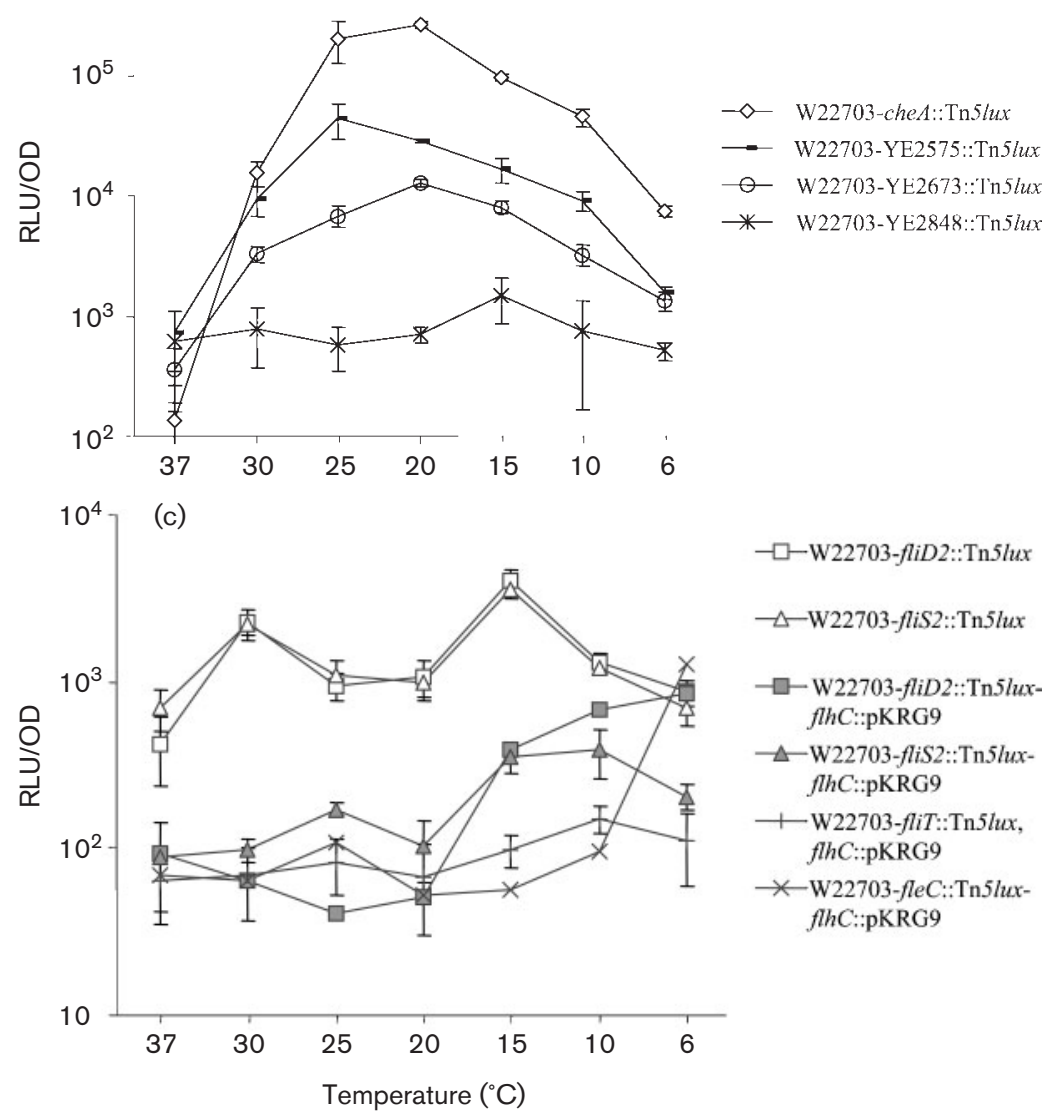

Fig. 2. Temperature-dependent expression of $Y$. enterocolitica W22703 genes involved in chemotaxis and motility. Overnight cultures were diluted 1:4000. RLU values were divided by $\mathrm{OD}_{405}$ values measured within a range of $0.8-0.9$. For each strain and temperature, the figure shows the mean $\pm S D$ of 3-16 independent measurements. (a) Five mutants with insertions of the luciferase reporter into Flag-1 genes show similar expression profiles, with maximal bioluminescence at approximately $20^{\circ} \mathrm{C}$. (b) Significantly weaker transcription is observed for the four genes involved in chemotaxis. (c) Temperaturedependent expression of the two Flag-2 genes fliD2 and fliS2. Upon flhC knockout, expression of both fliD2 and fliS2 is significantly reduced. As a control, the drastic decrease in fliT and fleC expression (compare with panel a) upon $\mathrm{flhC}$ knockout is also shown. of several double mutants in a $\mathrm{flaA}^{-}$background, the role of this additional flagellar subunit gene remains unclear. The distribution pattern of Flag-2 is similar to that of other genome domains, such as the insecticidal pathogenicity island $t c-\mathrm{PAI}^{Y e}$ (Bresolin et al., 2006b), indicating an evolutionary split of biotypes $1 \mathrm{~A}$ and $1 \mathrm{~B}$ from biotypes 2-5. We suggest that biotypes $2-5$, but not $1 \mathrm{~A}$ or $1 \mathrm{~B}$, use insects as transmission vectors, and that Flag-2 genes contribute to the fitness of pathogenic $Y$. enterocolitica outside their mammalian hosts, possibly by increasing the chance of encountering an invertebrate host.
We also tested the phenotype of three Flag-1 mutants. The non-motility of the fliF mutant is congruent with the finding that inactivation of fliF in Caulobacter crescentus (Grunenfelder et al., 2003) and Listeria monocytogenes (Bigot et al., 2005) abolishes flagella production and consequently bacterial motility. The increased motility of the fliT mutant indirectly confirms the finding that a Salmonella enterica sv. Typhimurium fliT:: kan mutant, in which flagellar structure and filament length were indistinguishable from those of wild-type flagella, produces twice as many flagella as the wild-type strain. However, no 
$15^{\circ} \mathrm{C}$

(a)

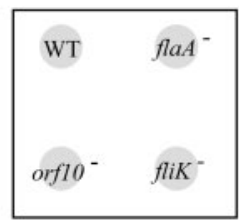

(b)

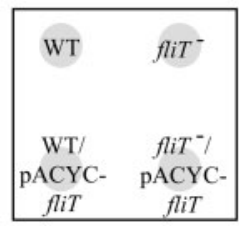

(c)

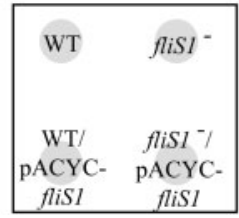

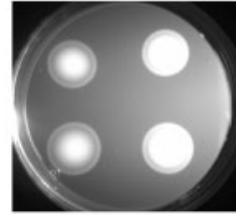
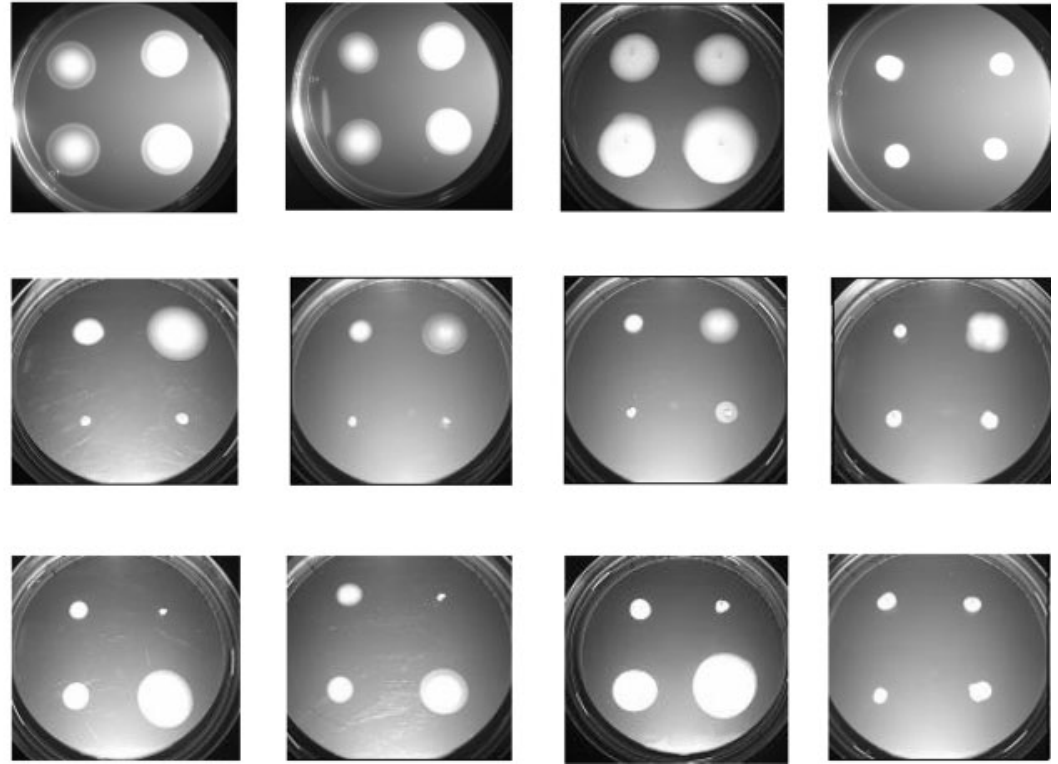

Fig. 3. Motility tests. W22703 wild-type strain (WT) and mutant strains were stabbed onto motility agar plates and monitored at $15,20,25$ and $30{ }^{\circ} \mathrm{C}$. Each experiment was repeated at least six times; representative data are shown. (a) Flag-2 mutants with inactivated orf10, fliK or flaA showed a significant increase in motility at lower temperature. (b) The W22703-fliT: :Tn5/ux mutant, which lacks a putative repressor of class 2 flagellar operons, is hyper-motile. (c) An insertional knockout of W22703fliS1::Tn5/ux, which putatively encodes a cytoplasmic chaperone, results in a non-motile phenotype. The two knockout mutations were complemented with pACYC184/fliS1 and pACYC184/fliT, respectively, thus restoring the wild-type phenotype.

corresponding phenotype of S. enterica sv. Typhimurium with increased motility could be identified (Yokoseki et al., 1995, 1996). The hyper-motile phenotype of the fliT mutant of $Y$. enterocolitica is in line with the assumption that FliT acts as a negative regulator of the transcription of flagellar genes (Kutsukake et al., 1999). This function is confirmed by our observation that even the wild-type strain showed a decreased motility as a result of fliT overexpression (Fig. 3b). In contrast, Y. enterocolitica motility was abolished in a fliS1 mutant. The motility of the fliS1 strain, but not of the wild-type, after FliS1 overexpression was significantly higher than that of the wild-type alone (Fig. 3c). This effect might be explained by a coupled transcription of fliS1 and fliT, so that strain W22703-fliS1::Tn5lux/pACYC-fliS1 genotypically resembles the hyper-motile fliT mutant. Flagellar filaments produced by a fliS mutant in S. enterica sv. Typhimurium were much shorter than those produced by the wild-type strain, indicating that FliS is a cytosolic chaperone involved in controlling flagellin polymerization and preventing FliC degradation (Auvray et al., 2001; Ozin et al., 2003). Motility of a Salmonella fliS mutant was clearly impaired but not completely abolished (Yokoseki et al., 1995).

A causal connection between motility and virulence has been demonstrated in several studies. At $37^{\circ} \mathrm{C}, Y$. enterocolitica cells are non-motile, autoagglutinate and express and secrete Yops. The invasion capabilitiy of this bacterium has been shown to be affected by motility, suggesting that motility is required for migrating to and contacting host cells (Young et al., 2000). The fliA gene, encoding the alternative $\sigma$ factor of the flagellar system, is highly induced at $25{ }^{\circ} \mathrm{C}$ and repressed at $37^{\circ} \mathrm{C}$ (Kapatral et al., 2004). FliA probably indirectly inhibits the expression at $25{ }^{\circ} \mathrm{C}$ of seven genes that are encoded by the pYV virulence plasmid, indicating that FliA plays a role in the inverse temperature regulation of flagellar and virulence genes (Horne \& Pruss, 2006). This observation is in line with the finding that a non-motile $f l h D C$ mutant of $Y$. enterocolitica also secretes larger amounts of Yops, encoded by the pYV plasmid, than the wild-type bacteria (Bleves et al., 2002). Evidence has also been found for a temperature-dependent synthesis antagonism between type III secretion in $Y$. enterocolitica, which is necessary for the survival of the bacterium in the mammalian host, and its flagellar assembly system (Bleves et al., 2002). The flagellar export apparatus functions as a secretion system for the virulence-associated phospholipase YplA (Young et al., 1999). Microarray data on S. enterica sv. Typhimurium motility have only recently revealed several FlhDCcontrolled virulence genes, among them the virulence operon $\operatorname{srf} A B C$, thus demonstrating that the association 
between motility and virulence is a phenomenon not restricted to Y. enterocolitica (Frye et al., 2006; Wang et al., 2004). Recently, it has been shown that in the insect pathogen Xenorhabdus nematophila the expression of a novel haemolysin, which is required for full virulence of $X$. nematophila against insects, is also regulated by the flagellar master-operon (Cowles \& Goodrich-Blair, 2005). Interestingly, within the scope of identifying genes that are upregulated during prolonged growth of $Y$. enterocolitica at low temperatures, e.g. during proliferation in insects, we identified a srfA homologue and a haemolysin secretion gene (Bresolin et al., 2006a). It might therefore be speculated that temperature-driven non-motility at $37{ }^{\circ} \mathrm{C}$ and maximal motility at approximately $20{ }^{\circ} \mathrm{C}$ essentially contribute to the control of the $Y$. enterocolitica switch between two pathogenicity phases related to mammals and invertebrates.

\section{ACKNOWLEDGEMENTS}

We thank Patrick Schiwek and Francesco Bruno for technical assistance, Kevin Francis for the gift of pUT mini-Tn5 luxCDABE $\mathrm{Km} 2$, Peter Roggentin, Alexander Rakin, Jürgen Heesemann, Henry Derschum and Herbert Nattermann for providing Y. enterocolitica strains, and anonymous reviewers for their helpful comments. This work was supported by a grant of the Hochschul- und Wissenschaftsprogramm (HWPII): Fachprogramm 'Chancengleichheit für Frauen in Forschung und Lehre' to G. B.

\section{REFERENCES}

Aldridge, P. \& Hughes, K. T. (2002). Regulation of flagellar assembly. Curr Opin Microbiol 5, 160-165.

Auvray, F., Thomas, J., Fraser, G. M. \& Hughes, C. (2001). Flagellin polymerisation control by a cytosolic export chaperone. J Mol Biol 308, 221-229.

Bigot, A., Pagniez, H., Botton, E., Frehel, C., Dubail, I., Jacquet, C., Charbit, A. \& Raynaud, C. (2005). Role of FliF and FliI of Listeria monocytogenes in flagellar assembly and pathogenicity. Infect Immun 73, 5530-5539.

Bleves, S., Marenne, M. N., Detry, G. \& Cornelis, G. R. (2002). Upregulation of the Yersinia enterocolitica yop regulon by deletion of the flagellum master operon flhDC. J Bacteriol 184, 3214-3223.

Bottone, E. J. (1997). Yersinia enterocolitica: the charisma continues. Clin Microbiol Rev 10, 257-276.

Bottone, E. J. (1999). Yersinia enterocolitica: overview and epidemiologic correlates. Microbes Infect 1, 323-333.

Bresolin, G., Neuhaus, K., Scherer, S. \& Fuchs, T. M. (2006a). Transcriptional analysis of long-term adaptation of Yersinia enterocolitica to low-temperature growth. J Bacteriol 188, 2945-2958.

Bresolin, G., Morgan, J. A., Ilgen, D., Scherer, S. \& Fuchs, T. M. (2006b). Low temperature-induced insecticidal activity of Yersinia enterocolitica. Mol Microbiol 59, 503-512.

Chang, A. C. \& Cohen, S. N. (1978). Construction and characterization of amplifiable multicopy DNA cloning vehicles derived from the P15A cryptic miniplasmid. J Bacteriol 134, 1141-1156.

Chilcott, G. S. \& Hughes, K. T. (2000). Coupling of flagellar gene expression to flagellar assembly in Salmonella enterica serovar Typhimurium and Escherichia coli. Microbiol Mol Biol Rev 64, 694-708.
Cornelis, G. \& Colson, C. (1975). Restriction of DNA in Yersinia enterocolitica detected by recipient ability for a derepressed $\mathrm{R}$ factor from Escherichia coli. J Gen Microbiol 87, 285-291.

Cowles, K. N. \& Goodrich-Blair, H. (2005). Expression and activity of a Xenorhabdus nematophila haemolysin required for full virulence towards Manduca sexta insects. Cell Microbiol 7, 209-219.

Fredriksson-Ahomaa, M., Stolle, A. \& Korkeala, H. (2006). Molecular epidemiology of Yersinia enterocolitica infections. FEMS Immunol Med Microbiol 47, 315-329.

Frye, J., Karlinsey, J. E., Felise, H. R., Marzolf, B., Dowidar, N., McClelland, M. \& Hughes, K. T. (2006). Identification of new flagellar genes of Salmonella enterica serovar Typhimurium. J Bacteriol 188, 2233-2243.

Fukushima, H., Ito, Y., Saito, K., Tsubokura, M. \& Otsuki, K. (1979). Role of the fly in the transport of Yersinia enterocolitica. Appl Environ Microbiol 38, 1009-1010.

Grunenfelder, B., Gehrig, S. \& Jenal, U. (2003). Role of the cytoplasmic C terminus of the FliF motor protein in flagellar assembly and rotation. J Bacteriol 185, 1624-1633.

Horne, S. M. \& Pruss, B. M. (2006). Global gene regulation in Yersinia enterocolitica: effect of FliA on the expression levels of flagellar and plasmid-encoded virulence genes. Arch Microbiol 185, 115-126.

Kapatral, V. \& Minnich, S. A. (1995). Co-ordinate, temperaturesensitive regulation of the three Yersinia enterocolitica flagellin genes. Mol Microbiol 17, 49-56.

Kapatral, V., Campbell, J. W., Minnich, S. A., Thomson, N. R., Matsumura, P. \& Pruss, B. M. (2004). Gene array analysis of Yersinia enterocolitica FlhD and FlhC: regulation of enzymes affecting synthesis and degradation of carbamoylphosphate. Microbiology 150, 2289-2300.

Kutsukake, K., Ikebe, T. \& Yamamoto, S. (1999). Two novel regulatory genes, fliT and $\mathrm{fliZ}$, in the flagellar regulon of Salmonella. Genes Genet Syst 74, 287-292.

Ochman, H., Ajioka, J. W., Garza, D. \& Hartl, D. L. (1990). Inverse polymerase chain reaction. Biotechnology (N Y) 8, 759-760.

Ozin, A. J., Claret, L., Auvray, F. \& Hughes, C. (2003). The FliS chaperone selectively binds the disordered flagellin C-terminal D0 domain central to polymerisation. FEMS Microbiol Lett 219, 219-224.

Parkhill, J., Wren, B. W., Thomson, N. R., Titball, R. W., Holden, M. T., Prentice, M. B., Sebaihia, M., James, K. D., Churcher, C. \& other authors (2001). Genome sequence of Yersinia pestis, the causative agent of plague. Nature 413, 523-527.

Rahuma, N., Ghenghesh, K. S., Ben Aissa, R. \& Elamaari, A. (2005). Carriage by the housefly (Musca domestica) of multiple-antibioticresistant bacteria that are potentially pathogenic to humans, in hospital and other urban environments in Misurata, Libya. Ann Trop Med Parasitol 99, 795-802.

Ren, C. P., Beatson, S. A., Parkhill, J. \& Pallen, M. J. (2005). The Flag-2 locus, an ancestral gene cluster, is potentially associated with a novel flagellar system from Escherichia coli. J Bacteriol 187, 1430-1440.

Rohde, J. R., Fox, J. M. \& Minnich, S. A. (1994). Thermoregulation in Yersinia enterocolitica is coincident with changes in DNA supercoiling. Mol Microbiol 12, 187-199.

Sambrook, J. \& Russell, D. W. (2001). Molecular Cloning: a Laboratory Manual, 3rd edn. Cold Spring Harbor, NY: Cold Spring Harbor Laboratory.

Simon, R., Priefer, U. \& Pühler, A. (1983). A broad host range mobilization system for in vitro genetic engineering: 
transposon mutagenesis in Gram-negative bacteria. Bio/technology 1, 784-791.

Thomson, N. R., Howard, S., Wren, B. W., Holden, M. T., Crossman, L., Challis, G. L., Churcher, C., Mungall, K., Brooks, K. \& other authors (2006). The complete genome sequence and comparative genome analysis of the high pathogenicity Yersinia enterocolitica strain 8081 . PLoS Genet 2, e206.

Wang, Q., Frye, J. G., McClelland, M. \& Harshey, R. M. (2004). Gene expression patterns during swarming in Salmonella typhimurium: genes specific to surface growth and putative new motility and pathogenicity genes. Mol Microbiol 52, 169-187.

Winson, M. K., Swift, S., Hill, P. J., Sims, C. M., Griesmayr, G., Bycroft, B. W., Williams, P. \& Stewart, G. S. (1998). Engineering the luxCDABE genes from Photorhabdus luminescens to provide a bioluminescent reporter for constitutive and promoter probe plasmids and mini-Tn5 constructs. FEMS Microbiol Lett 163, 193-202.
Yokoseki, T., Kutsukake, K., Ohnishi, K. \& lino, T. (1995). Functional analysis of the flagellar genes in the fliD operon of Salmonella typhimurium. Microbiology 141, 1715-1722.

Yokoseki, T., lino, T. \& Kutsukake, K. (1996). Negative regulation by $f l i D, f l i S$, and fliT of the export of the flagellum-specific antisigma factor, FlgM, in Salmonella typhimurium. J Bacteriol 178, 899-901.

Young, G. M., Schmiel, D. H. \& Miller, V. L. (1999). A new pathway for the secretion of virulence factors by bacteria: the flagellar export apparatus functions as a protein-secretion system. Proc Natl Acad Sci U S A 96, 6456-6461.

Young, G. M., Badger, J. L. \& Miller, V. L. (2000). Motility is required to initiate host cell invasion by Yersinia enterocolitica. Infect Immun 68, 4323-4326.

Edited by: P. W. O'Toole 